\title{
New results for the EIE-Surveyor project
}

\author{
J.M. Thiriet ${ }^{1}$, M. Robert ${ }^{2}$, M. J. Martins ${ }^{3}$, A. E. Ward ${ }^{4}$, \\ O. Bonnaud ${ }^{5}$, M. Hoffmann ${ }^{6}$, H. Yahoui ${ }^{7}$, H. Fremont ${ }^{8}$, all members EAEEIE \\ ${ }^{1}$ Université Joseph Fourier, IUT 1, Dépt. RT, BP 67, 38402 Saint Martin d'Hères cedex, France \\ ${ }^{2}$ ESSTIN, Université Henri Poincaré Nancy 1, France \\ ${ }^{3}$ Instituto Supérior Técnico, Universidade Tecnica de Lisboa, Portugal \\ ${ }^{4}$ University of York, United Kingdom \\ ${ }^{5}$ Groupe Microélectronique-IETR, Université de Rennes 1, France \\ ${ }^{6}$ Universität UIm, Institut für Mikrowellentechnik, Deutschland \\ ${ }^{7}$ Université Claude Bernard Lyon 1, France \\ ${ }^{8}$ Université Bordeaux 1, France \\ ${ }^{1}$ jean-marc.thiriet@ujf-grenoble.fr, ${ }^{2}$ michel.robertaesstin.uhp-nancy.fr, \\ ${ }^{3}$ mariajoaomartins@ist.utl.pt, ${ }^{4}$ aew6@york.ac.uk, ${ }^{5}$ olivier.bonnaud@univ-rennes1.fr, \\ ${ }^{6} \mathrm{Michael}$.Hoffmannauni-ulm.de, 'yahoui@cegely.univ-lyonl.fr, ${ }^{8}$ helene. fremontaims-bordeaux.fr
}

\begin{abstract}
The EIE-Surveyor ERASMUS thematic network has been launched in October 2005 for three years, the end will be in 2008. The purpose of this paper is to present a state of development of the outcomes developed within the project as well as the dissemination policy. This gives an overview of the results of the project, which are available freely from the web-site www.eie-surveyor.org.
\end{abstract}

\section{INTRODUCTION}

EIE-Surveyor is an ERASMUS thematic network which is funded by the European Commission for a three-year period until October 2008. Launched as an answer to a call for propositions from the European Commission, the aims of the project are globally to reflect and make concrete propositions for the problem of mobility of students, readability of contents, recognition of diploma.

The project is organised as four main tasks, each responsible for an outcome of the project, together with the corresponding activities and dissemination strategy. The coordination between the tasks and the global dissemination strategy is ensured thanks to the managing team of the project.

The main objectives of the four tasks are the following:

- reflection on generic competences and subject-specific competences in Electrical and Information Engineering (EIE) [1],

- implementation of quality assessment methodologies on some educational resources available in EIE,

- reflection and proposition of a methodology for accreditation, in order to enhance comparability and common certification procedures,

- proposition of a census of the existing curricula in EIE in Europe, the multinational degrees, and the situation of the implementation of the Bologna-process [2] in EIE, at the bachelor, master [3] and PhD levels.

The content of the project includes a survey and proposition of competencies, accreditation procedures, curricula contents and multinational degrees. The expected outcomes are:
- a report on generic and specific competences in Electrical and Information Engineering using the Tuning approach,

- a study on the present state of accreditation procedures at the European level, and throughout European countries,

- the proposition of a quality approach on some pedagogical resources reachable through internet,

- a state of the art of the implementation of the Bolognaprocess in Europe at the bachelor, master and doctoral study-levels.

Acting as a reference point for Electrical and Information Engineering in Europe, this project has been proposed and is achieved under the aegis of the EAEEIE (European Association for Education in Electrical and Information Engineering, www.eaeeie.org).

The second section describes the objectives of the project. The third section deals with the partnership. The fourth section presents the organisation of the project. The actual contents of the project are discussed in the fifth and sixth section, and the outputs are exposed in the seventh section. Before the conclusion, the eighth section proposes a photograph of the present state.

\section{OBJectives OF THE SURVEYOR TN}

In order to encourage students mobility at the European level and the diploma recognition, and also in order to facilitate readability of curricula and diploma, the EIESurveyor thematic network has been proposed in 2005, as an answer to a call from the European Commission.

This thematic network has been accepted for a three-year period. The activities of the project are the following:

- the setting of common definitions concerning competences (TUNING approach $[4,5]$ ) to define student courses, during their studies,

- analysis of accreditation procedures and methodologies in Europe (but also outside Europe) in order to make 
some common or shared propositions with the purpose to support content comparability and diploma recognition,

- the setting of a quality approach on some pedagogical resources available in EIE in Europe, in order to facilitate distant and lifelong learning,

- observation of the setting of the Bologna process in EIE in Europe, available study programmes, at the bachelor, master $[6,7]$ and doctoral levels, and the existence of international programmes...

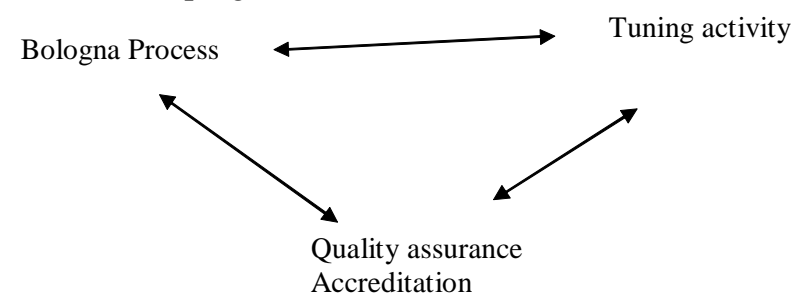

The main activity deals with competences (TUNING approach) which are important elements to be taken into account for the accreditation procedures which tend to improve student mobility and diploma recognition, the Bologna process being the mean to reach this goal.

\section{THE PARTNERSHIP}

29 eligible countries are represented in the consortium:

- 26 countries of the European Union (except Luxembourg), - Norway, Iceland, Turkey.

Two non eligible countries are represented in the consortium: Ukraine and Lebanon.

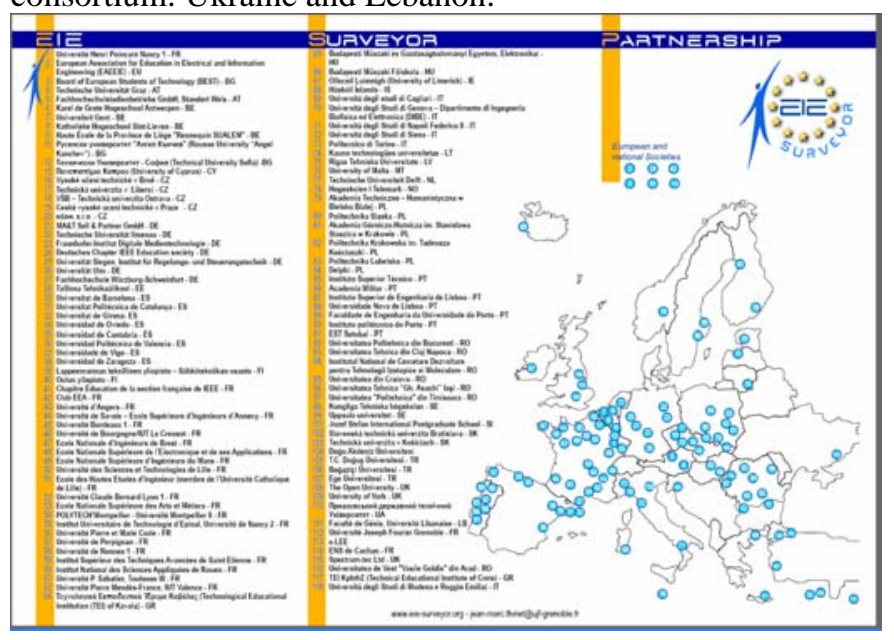

Figure 1: The EIE-Surveyor partnership

We can make some comments about the whole consortium.

- Some companies are present within the consortium: they contribute in the definition of competences, and also participate in some developments relative to the use of new technologies for teaching.

- Some research institutes are members; also various laboratories which belong to universities are indirectly members since many partners, as academic teachers belong both to a department for teaching and a laboratory, within their universities.

- Several societies are partners, such as BEST (Board of European Students of Technology), EAEEIE, IEEE French and German chapters on Education, French Club EEA (Club des Enseignants et des Chercheurs en Electronique, Electrotechnique et Automatique).

\section{ORGANISATION OF THE PROJECT}

The project is managed by a team of 6 people: O. Bonnaud (Université de Rennes 1, France), T. Ward (University of York, United Kingdom), M. Hoffmann (Universität Ulm, Germany), J. Liguš (University of Košice, Slovakia), G. Jervan (University of Tallinn, Estonia), MJ Martins (Instituto Superior Técnico, Lisboa, Portugal) who works in strong partnership with the coordinator of the project (JM Thiriet, Université Joseph Fourier Grenoble, France) and the account manager (Michel Robert, Université Henri Poincaré Nancy 1, France).

Each of the main activities of the project is managed by two or three co-ordinators:

- Task "TUNING": T. Ward (University of York, United Kingdom) and J. Jasenek (University of Bratislava, Slovakia),

- Task "Accreditation": D. Pasquet (ENSEA, Cergy, France), C. Burkley (University of Limerick, Ireland), F. Maciel-Barbosa (Universidade do Porto, Portugal),

- Task "Quality on pedagogical resources": J. MarzoLazaro (Universitat de Girona, Spain), D. Deniz (Eastern Mediterranean University),

- Task "Observatory of the Bologna process": MJ Martins (IST, Lisboa, Portugal), G. Jervan (University of Tallinn, Estonia), Hamed Yahoui (Université Claude Bernard Lyon 1, France).

A monitoring committee has been set in order to provide a feedback on the quality of the project, the outcomes ... This committee is presently managed by Hélène Frémont (Université de Bordeaux 1, France), assisted by JC Burguillo (Universidade de Vigo, Spain), M. Chmela (University of Brno, Czech Rep.) et Karl S. Guðmundsson (University of Reykjavik, Iceland).

This monitoring group took contact with external evaluators: H. Ferdinande (Belgium, representing TUNING project), V. de Kosinsky (Belgium, representing thematic networks in engineering), P. Lappalainen (Finland, former President of EAEEIE), J. Esteves (Portugal, representing CENELEC-Comité Européen de Normalisation Electrotechnique / European Committee for Electrotechnical Standardization).

Each year, a general meeting is organised (Santander, Spain in February 2006, Praha, Czech Rep in July 2007, Tallinn, Estonia on 29th June 2008, just before the 2008 EAEEIE annual conference, www.eaeeie.org), a working groups meeting (Craiova, Rumania in June 2006, Bratislava, Slovakia in March 2007, and Grenoble, France in March 2008) and an annual meeting of the managing team (Lyon, France in 
December 2005, Wels, Austria in December 2006, and Heraklion, Greece in December 2007).

\section{Content of the Project}

Today, in various European countries, universities and higher education institutions (HEIs) are organising their syllabi in conformity with the Bologna process [2]. The purpose of the Bologna process is to increase and enhance student and staff mobility, to allow diploma recognition and to attract students coming from extra-European countries, by presenting them the curricula proposed in Europe in the most comprehensive and attractive manner.

In the same time, the European Commission programmes encourage HEIs to work together in the development of common or shared curricula (see "Curriculum Development Programme") and particularly to improve the number of international curricula and to tend to excellence thanks to the ERASMUS MUNDUS programme [3].

\section{RUNNING ACTIVITIES}

EIE is actually the common substrate of all the most advanced technologies. So an important point is to get an observatory on the implementation of the Bologna-process in EIE: a tool for feedback, but also for colleagues. The aim of the project is to become a reference point in EIE. The general aim is also to enhance the attractiveness of ERA (European Research Area), the links with industry, and to participate to the continuous evolution of HE in Europe.

To answer to these needs, the main aims of this proposed thematic network are:

1. to implement the "Tuning project" $[4,5,8]$ approach in EIE, complementing the work done in other disciplines by the Tuning project itself and other thematic networks; the aim of this Tuning Approach is to identify and quantify the fields which have to be taught to a student, the generic competences (Line 1 of the tuning approach) as well as the subject-specific competences obtained (Line 2 of the Tuning approach): that is to register the competences in EIE.

Some reflections will be achieved also on "Diploma Supplement" (DS). DS has been proposed in order to facilitate European recognition. In the field of EIE and for the various levels (bachelor, master, $\mathrm{PhD}$ ), a template could be designed.

2. to tend to a methodology for accreditation [9]: for that, a preliminary study of the existing accreditation procedures has been done during the THEIERE project [10]. We should go further and complete the study in order to have a better view on the way the accreditation is done in the various countries, this point is strategic if we want to go further in the recognition of degrees and diploma all around Europe. The project will provide guidelines of good practices of accreditation based on the required competences and industry needs.

3. to incorporate Internet-based educational resources (elearning) for EIE education [11, 12]. For this purpose it is necessary first to have web available specific materials, covering the required EIE topics, and second computer supported tools to use these materials in a suitable way for attaining specific learning objectives and to allow different learning strategies (project based learning, collaborative / cooperative learning). This task deals with e-learning, for lifelong learning as well as initial education. To achieve the task's aim we propose to set up a mediatheque of pedagogical resources available through internet in EIE, as a census of existing resources. The aim is here to implement Quality in education to pedagogical resources in EIE available via Internet. On the one hand this means to select and classify educational materials for EIE on the basis of the quality of content in relation with the concepts, models and competences required in EIE, and the potential effectiveness as teachinglearning tools for EIE education; on the second hand, we will make them available to the EIE community. The work will be a continuation of some activities of the THEIERE project and completed with the selected resources.

4. to implement a survey of the Bologna process in EIE at the bachelor level, at the master level but also at the $\mathrm{PhD}$ level $[7,13]$. The activities will be the finalisation and update of the maps of European undergraduate and postgraduate studies: a monograph has been achieved during the THEIERE project (2000-2003), but some countries remain to be completed, some information needs to be updated because the situation is always evolving.

The main outputs of this action will be the update and completion of this monograph which will be available freely online.

\section{Planed OUTPUTS}

Expected outcomes for this project are:

- a report on competences (TUNING approach), which will be published for the colleagues and accreditation organisations,

- a report on accreditation procedures, which will be published mainly for accreditation organisations and colleagues responsible for study programmes,

- two monographs (one for the bachelor and master levels, one for the doctoral studies) presenting the various curricula existing in Europe in our disciplines, international curricula and the setting of the Bologna process,

- a report on the quality assessment methodology, which is proposed within the frame of the project,

- a leaflet presenting the project, to be disseminated to the colleagues and to the other thematic networks, and a website (www.eie-surveyor.org) from which it is possible to get all the outcomes of the project.

The dissemination of the project is a strategic activity. EIE (Electrical and Information Engineering) is the targeted thematic field, as well as applications based on these disciplines.

Targets of the project are:

- teachers and researchers in HEIs. The project should impulse the definition of new study programmes in our disciplines,

- students, direct users of the courses, 
- employers, as recipients of the students, in Europe and outside Europe,

- professional societies, for their knowledge of the evolution in the HEI landscape in Europe, and their participation to the accreditation.

Various target groups are some societies or associations such as French SEE (Société de l'Electricité, de l'Electronique et des Technologies de l'Information et de la Communication), British IEE (Institution of Electrical Engineers), American IEEE (Institute of Electrical and Electronics Engineers), Portuguese Ordem dos Engenheiros, French CNISF (Comité National des Scientifiques Français), French Club EEA (Club des Enseignants et des Chercheurs en Electronique, Electrotechnique et Automatique), German Verein Deutscher Ingenieure (VDI), German Verein Deutscher Elektrotechniker (VDE)... as well as student associations in various countries and at the European level (BEST, Board of European Students of Technology).

\section{PREsent Stage Of The Project}

The purpose of this TN is to participate in the setting of the academic world for tomorrow. Several tools and methodologies are studied and proposed by the whole consortium, representative of the various countries and academic systems, the various subfields of Electrical and Information engineering, and the various levels (BachelorMaster-Doctorate) of the Bologna process.

Several aspects will also be studied in partnership and coherence with other scientific and technological TNs (TREETeaching and Research in Engineering in Europe, EUCEETEUropean Civil Engineering Education and Training, EEGECS-European Education in Geodetic Engineering, Cartography and Surveying, USAEE-University Studies of Agricultural Engineering in Europe ...) in the frame of the Archipelago transversal action.

The project running and results are constantly evaluated thanks to the setting of a monitoring group, including both internal and external reviewers.

\section{CONCLUSION}

Before to conclude, we can point out the fact that a reflection is done also within the project in order to attract students to the scientific studies (particularly in EIE) and also to attract women, since women are less present in our disciplines. Contacts have been established with TNs dedicated on these aspects.

EIE-Surveyor being now at the last stage, a new application has been submitted, by the consortium, within the LifelongLearning Programme.

On the strategic point of view, we may say this project is very important since it brings a contribution in the second stage of the development of a unified HEI landscape in Europe. After the ERASMUS-ECTS tools invented by the European Commission in order to help universities to facilitate student mobility, the next stage is to go further in the improvement of the visibility and comparability of our degrees and curricula, in order to allow mobility, attract foreign students and facilitate recognition of diploma, on a world basis...

\section{ACKNOWLEDGMENT}

The authors wish to thank the European Commission for the grant and all the partners of the project for their contribution.

\section{REFERENCES}

[1] Thiriet J.M., M. Robert, P. Lappalainen, M. Hoffmann, M. J. Martins and A. Seoane, Toward a pan-European virtual university in Electrical and Information Engineering, IEEE trans. on Education, Vol.45, n. 2, May 2002, pp.152-160.

[2] Bologna declaration, Bologna declaration, European Commission, Brussels, Bologna, 1999.

[3] H. Yahoui, O. Roesch, J.M. Thiriet, M. J. Martins and O. Bonnaud, Evolution of master degree in Europe: An overview of the European programme available in electrical and information engineering, EIEEIE'05 Conference, Lappeenranta, Finland, June 2005, pp. 49-52.

[4] Tuning, Tuning Educational Structure in Europe. Final Report Pilot Project - Phase 1, Tuning project, Ed. J. Gonzalez and R. Wagenaar, Deusto and Groningen, 2005.

[5] Tuning, Tuning Educational Structure in Europe. Final Report Pilot Project - Phase 2, Tuning project, Ed. J. Gonzalez and R. Wagenaar, Deusto and Groningen, 2005.

[6] Tauch C. and A. Rauhvargers, Survey on Master Degrees and Joint Degrees in Europe, EUA/European Union, Brussels, 2002.

[7] Collective, under the co-ordination of J.M. Thiriet \& M.J. Martins, Monograph: Towards the harmonisation of Electrical and Information Engineering Education in Europe, Ed. EAEEIE, Nancy \& Lisboa, August 2003, 350 pages.

[8] A. Ward, J. Jasenek and J.M. Thiriet, The application of the Tuning Methodology to the Electrical and information Engineering Disciplines, an EIE Surveyor Project, $18^{\text {th }}$ EAEEIE Annual Conference on Innovation in Education for Electrical and Information Engineering (EIE), EAEEIE'2007, July $2^{\text {nd }}-4^{\text {th }}, 2007$, Praha (Cesko), ISBN 978-8001-03745-4.

[9] F. Maciel Barbosa, Cyril Burkley, Michael H.W. Hoffmann, and Jean Marc Thiriet, Accreditation of higher education in EIE in Europe, 18th EAEEIE Annual Conference on Innovation in Education for Electrical and Information Engineering (EIE), EAEEIE'2007, July $2^{\text {nd }}-4^{\text {th }}, 2007$, Praha (Cesko), ISBN 978-80-01-03745-4.

[10] Martins M.J., M. Robert and J.M. Thiriet, A thematic network contribution to education and training in electrical and information engineering in Europe, 4th ITHET'03 Conference, Marrakech, Morocco, 2003 July 7-9 (CD-ROM).

[11] D. Denis, J.L. Lazaro, S. Stefanova, J.-M. Thiriet, Cataloguing and Quality Assessment of Some Resources in EIE Available Through the Internet, $18^{\text {th }}$ EAEEIE Annual Conference on Innovation in Education for Electrical and Information Engineering (EIE), EAEEIE'2007, July $2^{\text {nd }}-4^{\text {th }}, 2007$, Praha (Cesko), ISBN 978-80-01-03745-4.

[12] M.J. Martins, J.M. Thiriet, O. Bonnaud, M. Robert, Quality-based network for Curricula Harmonisation, Proceedings of CATE 2005 conference, Aruba, August 2005, (CD-ROM)

[13] J.M. Thiriet, M.J. Martins, H. Yahoui, M. Robert, H. Fremont, EIESurveyor: Observatory of the Bologna-process in EIE: an aid for the enhancement of mobility, $18^{\text {th }}$ EAEEIE Annual Conference on Innovation in Education for Electrical and Information Engineering (EIE), EAEEIE'2007, July $2^{\text {nd }}-4^{\text {th }}, 2007$, Praha (Cesko), ISBN 978-8001-03745-4. 